Methods Understand the factors leading to migration. Examine global evidence on initiatives to retain a competent and motivated health workforce, whether from North to South and vice versa or East to west and vice versa. The review draws on literature and information gathered through a targeted search of websites and databases regarding migration of health care workers

Results Decision-making factors and responses to financial and non-financial incentives have not been adequately monitored and evaluated.

Conclusion Efforts must be made to build evidence base so that countries can develop appropriate workforce strategies and incentive packages.

\section{9b ANALYSING THE MIGRATION CORRIDORS OF WOMEN IN LATIN AMERICA}

I Bello. University of Carabobo, Valencia, Venezuela

\subsection{6/oemed-2018-ICOHabstracts. 1513}

The challenges of the globalised economy, the increase of international transportation and other technological developments should make migration an easy move for those interested in moving to and from other countries. However this is not the common scenario of migrant workers, particularly women. Globalisation, economic crises, unemployment and increasing poverty have prompted many workers in low income countries of the Americas to seek work out of their country of origin. Women have done so but mostly reaching low-skilled-labour.

The phenomenon of migration affects Latin America and the Caribbean, just as the rest of the world. It continues to increase in volume, dynamic s and complexity since several decades, and is strongly linked to people chasing better opportunities of employment, income and work. Most of the countries are involved either as destination, transit or origin for migrators. The United States is by far the most attractive destination for most migrant workers of Latin America (ILO, 2016). However, there are also many intra-regional destinations such as Argentina, Barbados, Brazil, Costa Rica, Chile, Dominican Republic, Panama, Canada and Trinidad and Tobago; as well as other trans-continental destinations including Spain, Italy and Portugal.

This presentation will make an overview of the recommendations of ILO Regional Report, the Organisation of American States OAS, the Pan-American Health Organisation PAHO, and the Economic Commission for Latin America and the Caribbean ECLAC, within others. It will highlight the challenges migrant workers face for achieving better working, equitable and fair migration, often worst for women than for men. It also illustrates critical cases of inequities between and within countries, trying to understand the needs of the everchanging migration movements, and the concentration of migration in low-skilled work such as construction, agriculture, domestic servers and homecare, within other occupations. And the conditions under which workers are integrated to the labour market (salaries, working conditions, health and safety, social protection, etc.).

In conclusion, although the phenomenon is now more visible due to research, social media and communication technologies reaching all corners of the world, policy and governance challenges remain to be a target for improving the conditions of working migrants, particularly women, in the Americas. This is an invitation to maintain research of this phenomena as a priority.

\section{9c GLOBAL HEALTH CHALLENGES AND ILO POLICY RESPONSES FOR MIGRANT WORKERS}

N Leppink. International Labour Organisation, Geneva, Switzerland

\subsection{6/oemed-2018-ICOHabstracts.1514}

The estimated number of migrant workers has reached 150.3 million, of these 66.6 million are women. 11.5 million are domestic workers with the vast majority of domestic workers, 8.5 million, being women. Migrant workers are at a significantly greater risk of being injured or becoming ill due to work in large part because they are engaged in $3 \mathrm{D}$ jobs. When they are injured or become ill due to work, few are covered by the social protection laws of the countries where they are working and even if covered face significant barriers to accessing needed assistance and services.

The ILO promulgated international standards and related instruments which address many of these challenges including conventions and recommendations on Migrant Workers (C. 97, C.143, R. 86, R. 151), Social Protections (C. 118, C. 157, R. 167) and Domestic Workers (C. 189, R. 201). Domestic work is one of the least regulated sectors of the economy and, as such, is of particular concern to the ILO due to its concentration of migrant women workers and relatively low visibility of the workforce.

More recently the ILO has launched a fair recruitment initiative in response to concerns about the growing role of unscrupulous employment agencies, informal labour intermediaries and other operators acting outside the legal and regulatory framework that prey especially on low-skilled workers. The ILO is also playing a leading role in development of the Compact for Migration and the inclusion of provisions addressing migrant worker health along with the IOM and WHO. The global compact is a significant opportunity to improve the governance on migration, to address the challenges associated with today's migration, and to strengthen the contribution of migrants and migration to sustainable development.

\section{WOMEN HISTORY AND CHALLENGES WORKING IN THE ARMED FORCE}

${ }^{1}$ Marta Prado, ${ }^{2}$ Claudio García, ${ }^{3}$ Osvaldo Birreci. ${ }^{1}$ Head of the Occupational Health Service of Laboratorios Elea Argentina; ${ }^{2}$ Chief of Occupational Medicine of the Atucha Nuclear Power Plant of Argentina; ${ }^{3}$ Doctor of Preventive Medicine of the Aeronautical Direction of Argentina

\subsection{6/oemed-2018-ICOHabstracts. 1515}

Introduction The Argentine Republic is a nation where women workers have struggled exhaustively to insert themselves in the working field, having achieved a relatively positive change during the last decades. Beyond this new and prosperous paradigm for women, it must be acknowledged that one of the places where a substantial change is observed is in the armed forces, where historically the role of women has been relegated to a secondary plane, fulfilling tasks of support to complement the tasks of male workers. Nowadays, it is a fact that 